\title{
Hydrogen sulfide alleviates cognitive deficiency and hepatic dysfunction in a mouse model of acute liver failure
}

\author{
DA-SEN YUAN ${ }^{*}$, YUE-QI HUANG ${ }^{*}$, YUAN-JI FU* ${ }^{*}$ JUAN XIE, \\ YUAN-LU HUANG, SHI-SHAN ZHOU, PEI-YUAN SUN and XIAO-QING TANG \\ Institute of Neuroscience, University of South China, Hengyang, Hunan 421001, P.R. China
}

Received June 26, 2019; Accepted March 17, 2020

DOI: $10.3892 /$ etm.2020.8680

\begin{abstract}
Acute liver failure (ALF) is a devastating clinical syndrome with a high mortality rate if not treated promptly. Previous studies have demonstrated the beneficial effects of hydrogen sulfide $\left(\mathrm{H}_{2} \mathrm{~S}\right)$ on the brain and liver. The present study aimed to investigate the potential protective effects of $\mathrm{H}_{2} \mathrm{~S}$ in ALF. A mouse model of ALF was established following treatment with thioacetamide (TAA). Mice with TAA-induced ALF were intraperitoneally injected with 30 or $100 \mu \mathrm{mol} / \mathrm{kg} /$ day sodium hydrosulfide (NaHS; a $\mathrm{H}_{2} \mathrm{~S}$ donor drug) for two weeks. According to results from novel object recognition and Y-maze tests, in the present study, NaHS treatment alleviated cognitive deficiency and preserved spatial orientation learning ability in TAA-induced ALF mice compared with those of untreated mice. In addition, NaHS treatment reduced serum levels of aspartate transaminase (AST), alanine transaminase (ALT) and the concentration of ammonia compared with those that received control treatment, resulting in weight loss prevention. These findings suggested a beneficial effect of $\mathrm{H}_{2} \mathrm{~S}$ on liver function. In conclusion, results from the present study suggested that $\mathrm{H}_{2} \mathrm{~S}$ treatment may alleviate cognitive deficiency and hepatic dysfunction in mice with ALF, indicating the potential therapeutic benefits of applying $\mathrm{H}_{2} \mathrm{~S}$ for the treatment of ALF.
\end{abstract}

\section{Introduction}

Acute liver failure (ALF) is a devastating clinical syndrome that is associated with a high mortality rate if not treated promptly (1). Originally termed fulminant hepatic failure, ALF is defined as severe liver injury that is potentially revers-

Correspondence to: Dr Xiao-Qing Tang, Institute of Neuroscience, University of South China, 28 West Chang-sheng Road, Hengyang, Hunan 421001, P.R. China

E-mail: tangxq-usc@usc.edu.cn

*Contributed equally

Key words: acute liver failure, cognition, hydrogen sulfide, novel object recognition test, Y-maze test ible in nature with the onset of hepatic encephalopathy (HE) occurring within 8 weeks of the first symptoms in the absence of any pre-existing liver diseases (2). Patients ALF with HE present with various neuropsychiatric symptoms, including cognitive deficiency, motor function impairment and alterations in personality and consciousness $(3,4)$. Although the most effective therapy for ALF is liver transplantation, due to the side effects associated with immunosuppressant therapy and the shortage of donor organs, this procedure is limited at present $(5,6)$. Therefore, further investigation into novel approaches for the treatment of ALF is urgently sorted.

Hydrogen sulfide $\left(\mathrm{H}_{2} \mathrm{~S}\right)$ was previously known only for its unpleasant odor; however, an increasing number of studies have revealed that endogenously produced $\mathrm{H}_{2} \mathrm{~S}$ serves a protective role in a number of physiological functions (7). Numerous enzymes, including cystathionine- $\gamma$-lyase (CSE), cystathionine- $\beta$-synthase and 3-mercaptopyruvate sulfurtransferase are responsible for $\mathrm{H}_{2} \mathrm{~S}$ synthesis (8). In the liver, endogenously produced $\mathrm{H}_{2} \mathrm{~S}$ participates in the regulation of liver glucose metabolism, lipoprotein synthesis, hepatic circulation, liver bioenergetics and oxidative stress (8). A number of studies have previously revealed the protective effects of $\mathrm{H}_{2} \mathrm{~S}$ in multiple models of hepatic diseases, including liver cirrhosis and fibrosis (9), portal hypertension (10) and hepatic ischemia-reperfusion (I/R) injury (11). In addition, $\mathrm{H}_{2} \mathrm{~S}$ has also been demonstrated to be a novel signaling molecule and neuromodulator in the central nervous system (12). Previous evidence has indicated that $\mathrm{H}_{2} \mathrm{~S}$ protects neurons from oxidative stress and impairments of learning and memory in models of Alzheimer's disease $(13,14)$. Therefore, it could be hypothesized that $\mathrm{H}_{2} \mathrm{~S}$ may also exert protective role son mouse models of ALF, with combined effects on both the brain and liver.

In the present study, ALF was induced in mice by thioacetamide (TAA) treatment, where sodium hydrosulfide (NaHS) served as the $\mathrm{H}_{2} \mathrm{~S}$ donor. The results of the present study revealed that $\mathrm{H}_{2} \mathrm{~S}$ treatment alleviated cognitive deficiency and preserved spatial orientation learning ability as assessed by novel object recognition (NOR) and Y-maze tests, respectively. In addition, $\mathrm{H}_{2} \mathrm{~S}$ treatment reduced serum aspartate transaminase (AST), alanine transaminase (ALT) and ammonia levels and prevented weight loss following ALF induction. These results suggested a protective effect of $\mathrm{H}_{2} \mathrm{~S}$ in ALF-model 
mice, indicating that $\mathrm{H}_{2} \mathrm{~S}$ may serve as a potential therapeutic agent for ALF.

\section{Materials and methods}

Animals. A total of 100 female Institute of Cancer Research mice (age, 8 weeks; weight, $30 \pm 2 \mathrm{~g}$ ) were provided by the Hunan SJA Laboratory Animals Co., Ltd. and were housed individually in a well-ventilated and temperature-controlled room (temperature, $25^{\circ} \mathrm{C}$; humidity, 50\%) under a 12 -h light/dark cycle, with free access to food and water. The mice had 7 days to habituate to their new environment before they were subjected to experiments. All experiments were conducted in accordance with the National Institutes of Health Guide for the Care and Use of Laboratory Animals (15) and were approved by the Animal Use and Protection Committee of the University of South China (Hengyang, China). All efforts were made to minimize the number of animals used and their suffering.

Drugs and treatments. NaHS, the $\mathrm{H}_{2} \mathrm{~S}$ donor and TAA were purchased from Sigma-Aldrich; Merck KGaA. NaHS and TAA were dissolved in phosphate buffered saline (PBS) and sterile normal saline solutions, respectively. Following 7 days of adaptation, the mice were randomly divided into five treatment groups ( $n=20$ per group; Fig. 1): i) The control group, in which mice were injected intraperitoneally with PBS for 14 days; ii) the TAA-alone-treatment group, in which mice were injected intraperitoneally with $150 \mathrm{mg} / \mathrm{kg} / \mathrm{day}$ TAA for 3 days; iii) the co-treatment with TAA and $30 \mu \mathrm{mol} / \mathrm{kg} / \mathrm{day} \mathrm{NaHS}$ group, in which mice were pre-treated with $30 \mu \mathrm{mol} / \mathrm{kg} /$ day NaHS for 11 days and subsequently co-treated with $150 \mathrm{mg} / \mathrm{kg} / \mathrm{day}$ TAA for 3 days; iv) the co-treatment with TAA and $100 \mu \mathrm{mol} / \mathrm{kg} /$ day NaHS group, in which the mice were pre-treated with $100 \mu \mathrm{mol} / \mathrm{kg} /$ day NaHS for 11 days and subsequently co-treated with $150 \mathrm{mg} / \mathrm{kg} / \mathrm{day}$ TAA for 3 days; and v) the NaHS-alone-treated group, in which mice were injected intraperitoneally with 100 $\mu \mathrm{mol} / \mathrm{kg} /$ day NaHS for 14 days. A well-established model of TAA-induced ALF was used (16-18). Following TAA injection for $24 \mathrm{~h}$, all animals, including those in the control group, were subcutaneously injected with $0.5 \mathrm{ml}$ solution containing $0.45 \% \mathrm{NaCl}, 5 \%$ dextrose and $0.2 \% \mathrm{KCl}$ to prevent the development of hypovolemia, hypoglycemia and hypokalemia, respectively. Hypothermia was prevented by intermittent exposure to infrared light in a procedure described previously $(19,20)$.

Survival analysis after TAA challenge. Survival rates in each group were recorded on the mornings of days 15-18. Housing was maintained at a temperature of $25^{\circ} \mathrm{C}$ and relative humidity of $50 \%$ to reduce animal suffering. Baseline body weight was measured at 8:00 am on the first day of TAA injection and body weight was subsequently recorded three times per day (at the beginning of the day and every 6 $\mathrm{h}$ between 8:00 am and 8:00 pm). Animals were euthanized by sodium pentobarbital overdose $(100 \mathrm{mg} / \mathrm{kg}$, intravenous injection) when a reduction of $>20 \%$ baseline body weight was observed. All mice were euthanized when all the measurements were completed.
NOR test. Mice cognitive function was assessed by using a novel objection recognition analysis system (BW-NOD405; Shanghai Biowill Co., Ltd.). NOR test was performed once per day after the induction of ALF. The NOR test included three trials. In the habituation phase, all mice were habituated in a $38 \times 38 \times 38 \mathrm{~cm}$ test box for 2 days. All individuals were allowed to explore the empty arena for $5 \mathrm{~min}$ once per day. On day 3 of the NOR test, the mice were allowed to explore two identical objects that were placed at opposite corners of the box for $5 \mathrm{~min}$, in a process known as the familiarization phase. Following a 1-h retention interval, the mice underwent a test session in the box with one familiar and one novel object. Each animal was allowed to explore the objects for $5 \mathrm{~min}$, where the exploration time spent for each object was recorded. Ethanol $(75 \% \mathrm{v} / \mathrm{v})$ was used to wipe the objects and the test apparatus prior to each test to avoid olfactory cue formation. Sniffing and touching of the objects (distance within $1 \mathrm{~cm}$ ) were considered exploratory behaviors, whilst climbing on the objects or chewing were not. Discrimination index, which was calculated as the time difference between new and familiar object exploration/total time, was adopted to evaluate animal cognitive function $(21,22)$.

Y-maze test. Spatial orientation learning ability was assessed by using a Y-maze analysis system (BW-MYM103; Shanghai Biowill Co., Ltd.). The Y-maze test was performed 4 days following the induction of ALF. The Y-maze was divided into three arms (A, B and C) with an angle of $120^{\circ}$ between them. The size of each arm was $50 \times 18 \times 35 \mathrm{~cm}$. Each mouse was habituated in the Y-maze for $10 \mathrm{~min}$ prior to the test. Subsequently, the mice were placed into the first arm and allowed to move freely for $5 \mathrm{~min}$. Arm entry was recorded when all four limbs of the mouse completely entered the arm. The appropriate alternating sequence was defined as three consecutive entries made into the different arms, whilst animals that entered the same arm three times consecutively were considered to have performed an incorrect alternating sequence. Ethanol $(75 \% \mathrm{v} / \mathrm{v})$ was used to wipe the objects and the test apparatus prior to each test in order to remove olfactory cues. A spontaneous alternation score was estimated to measure spatial orientation learning ability (23).

Serum ammonia and liver enzymes. Blood samples (500 $\mu \mathrm{l})$ were obtained from each mouse via the orbital vein after $\mathrm{Y}$ maze test under anesthesia with an intraperitoneal injection of sodium pentobarbital $(50 \mathrm{mg} / \mathrm{kg})$. After blood extraction, all mice were euthanized by sodium pentobarbital overdose (100 mg/kg, intravenous injection). ALT, AST and ammonia levels were analyzed in glass tubes, following the Y-maze test. Serum samples were centrifuged (speed, $1006.2 \mathrm{x}$ g; temperature, $37^{\circ} \mathrm{C}$ ) for $5 \mathrm{~min}$ and analyzed on the day of sampling using a Hitachi 7600 series Automatic Analyzer (Hitachi, Ltd.). All serum samples were processed in the same laboratory using the same methods and reference values.

Statistical analysis. Statistical analysis was performed using the SPSS 18.0 software (SPSS, Inc.). The data are presented as the mean \pm SEM. One-way ANOVA with the least-significant difference multiple comparison test (where there were 3 groups) or Tukey's post hoc test (where there 


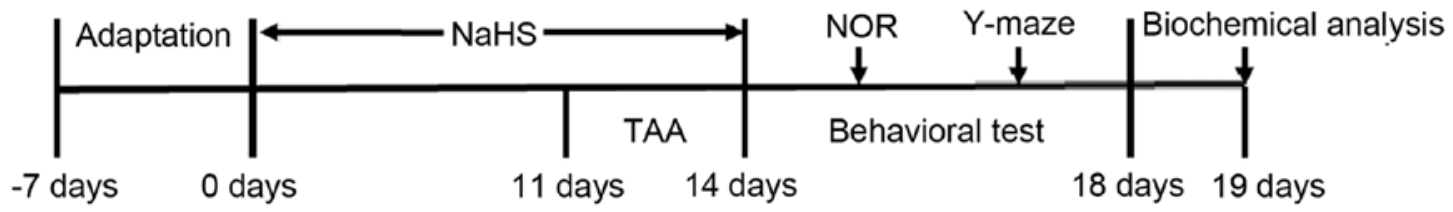

Figure 1. Schematic diagram of the experimental schedule. NOR, novel object recognition test; TAA, thioacetamide; NaHS, sodium hydrosulfide.

A

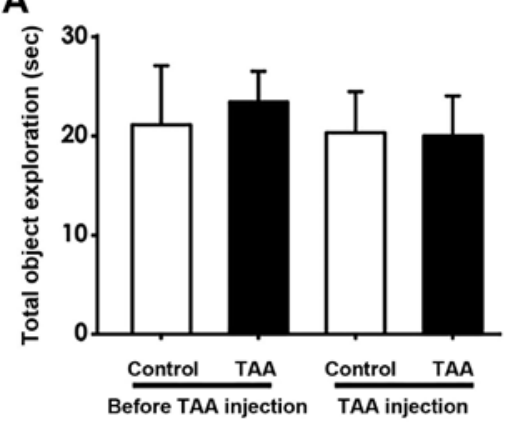

C

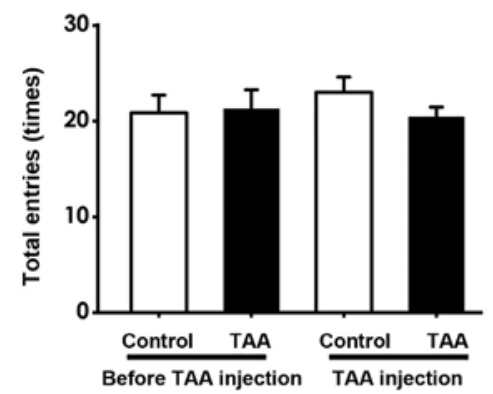

B

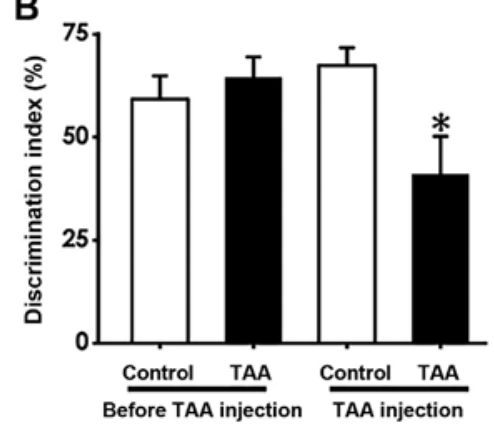

D

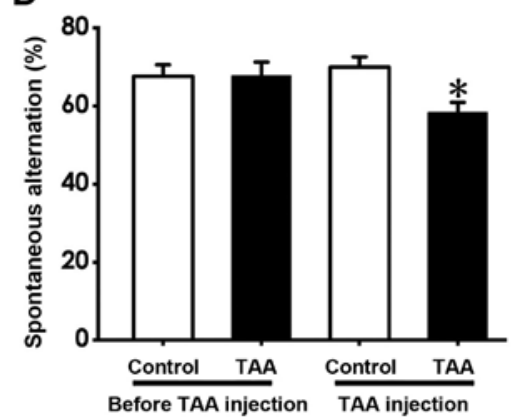

Figure 2. Effect of TAA on mouse cognitive function in the NOR and Y-maze tests. The NOR and Y-maze tests were adopted to evaluate cognitive function before and after TAA administration. (A) The total object exploration time and (B) discrimination index in the test period were recorded for each mouse. The NOR test results are presented as the mean \pm SEM. $n=8-9$. (C) The total number of arm entries and (D) spontaneous alternations were recorded for each mouse. Y-maze test values are presented as the mean \pm SEM. $n=9-15$. ${ }^{*} \mathrm{P}<0.05$ vs. TAA, before TAA injection. NOR, novel object recognition test; TAA, thioacetamide.

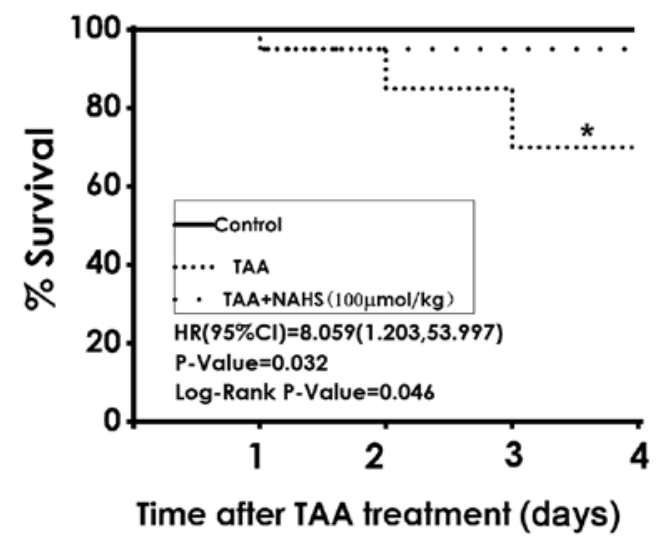

Figure 3. Effect of NaHS treatment on the survival rates of mice. The mortality rates in each group were recorded from days 15 to 18 after TAA treatment. $\mathrm{n}=20 .{ }^{*} \mathrm{P}<0.05$, TAA vs. TAA + NaHS $(100 \mu \mathrm{mol} / \mathrm{kg})$. NaHS, sodium hydrogen sulfide; TAA, thioacetamide.

were $>4$ groups) was performed. Kaplan-Meier survival analysis was performed using the Cox proportional hazards regression and the Log-rank test. Weight data was processed using mixed-design ANOVA and one-way ANOVA, following which Bonferroni's test was used as the post hoc test for simple main effects. $\mathrm{P}<0.05$ was considered to indicate a statistically significant difference.

\section{Results}

TAA induces cognitive deficiency as demonstrated by the NOR and Y-maze tests. NOR and Y-maze tests were performed to evaluate mouse cognitive function following and prior to TAA treatment $(150 \mathrm{mg} / \mathrm{kg}$, intraperitoneally). The NOR test revealed that the discrimination index in TAA-treated mice was significantly reduced following TAA injection compared with that in the TAA group prior to injection (Fig. 2B). However, no significant difference was observed between the total time spent exploring the novel object prior to and following TAA injection (Fig. 2A). In the Y-maze test, the number of spontaneous alternations made by mice were found to be significantly decreased following TAA treatment compared with those prior to TAA treatment (Fig. 2D), whilst no significant differences were observed in the number of total entries made by the mice prior to and following TAA injection (Fig. 2C). These 

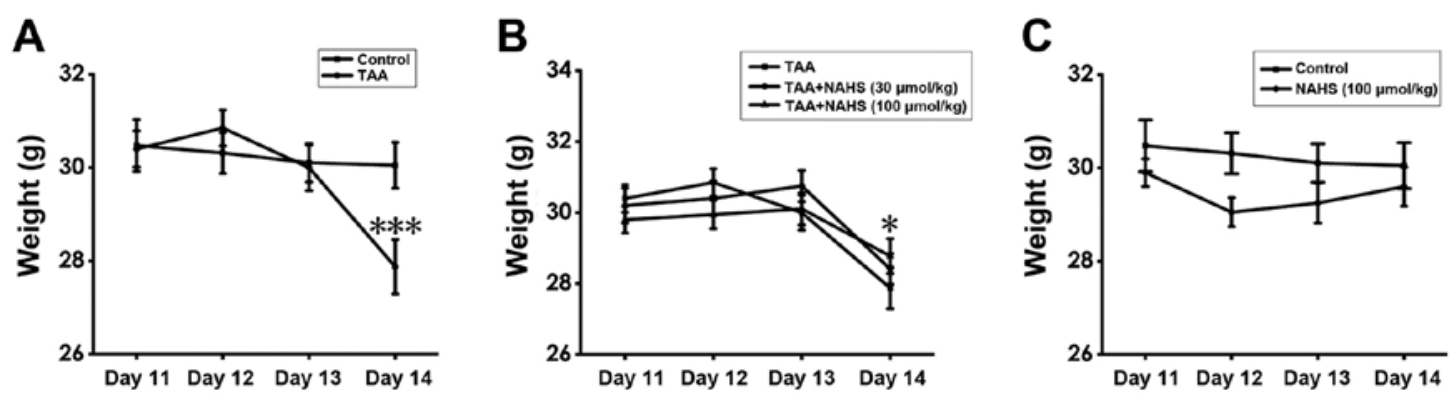

Figure 4. Effect of $\mathrm{H} 2 \mathrm{~S}$ on the body weight of each mouse. Weight changes were recorded in the mornings from days 11 to 14 after TAA treatment. (A) Comparison between control and TAA groups, (B) comparison among TAA-treated-alone goup and co-treatment with TAA and NaHS (30 and $100 \mu \mathrm{mol} /$ $\mathrm{kg} / \mathrm{day}$, intraperitoneally) groups, and (C) comparison between control and NaHS (100 $\mu \mathrm{mol} / \mathrm{kg} / \mathrm{day}$, intraperitoneally) groups. Values are presented as the mean \pm SEM. $n=9-15 .{ }^{* * *} \mathrm{P}<0.001$ vs. control; ${ }^{*} \mathrm{P}<0.05$ vs. TAA. H2S, hydrogen sulfide; TAA, thioacetamide; NaHS, sodium hydrogen sulfide.

A

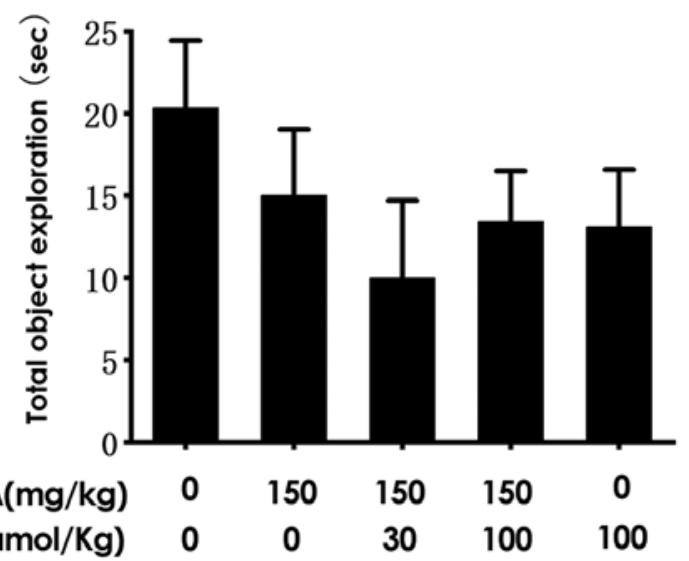

B

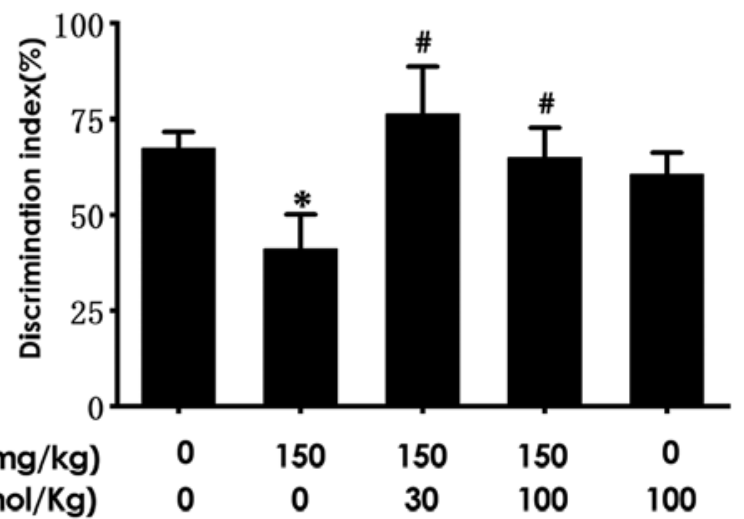

Figure 5. Effect of $\mathrm{H}_{2} \mathrm{~S}$ on the novel object recognition ability of mice following TAA treatment. After treatment with saline or NaHS (30 and $100 \mu$ mol/ $\mathrm{kg} / \mathrm{day}$, intraperitoneally) for 11 days followed by co-treatment with TAA ( $150 \mathrm{mg} / \mathrm{kg}$, intraperitoneally) for 3 days, the mice were subjected to novel object recognition test. (A) The total object exploration time and (B) discrimination index in the test period were recorded for each mouse. Values are presented as the mean \pm SEM $n=8-9$. ${ }^{*} \mathrm{P}<0.05$ vs. control; ${ }^{~} \mathrm{P}<0.05$ vs. TAA. NaHS, sodium hydrogen sulfide; TAA, thioacetamide.

results suggest that TAA treatment resulted in cognitive deficiency.

$\mathrm{H}_{2} \mathrm{~S}$ improves the survival rate of TAA-treated mice. The results of the present study revealed that 6 of the 20 mice did not survive to day 18 following TAA administration (150 mg/kg, intraperitoneally), whilst all mice in the control group were viable. NaHS treatment $(100 \mu \mathrm{mol} / \mathrm{kg} / \mathrm{day}$, intraperitoneally) significantly reduced the mortality rate in the co-treatment group, where 1 of the 20 mice did not survive ( $\mathrm{P}=0.046$; Fig. 3). These results demonstrated that $\mathrm{H}_{2} \mathrm{~S}$ treatment improved the survival rates of ALF mice.

$\mathrm{H}_{2} \mathrm{~S}$ prevents weight loss in TAA-treated mice. To assess weight changes in the mice among the treatment groups over time, a mixed ANOVA was conducted. The results showed that the main effect of treatment regimen was not significantly different $(\mathrm{F}=0.549 ; \mathrm{P}=0.76)$ and the subsequent post-hoc test for the main effects of treatment regimen also did not reveal any significant differences. However, the main effect of time $(\mathrm{F}=34.609 ; \mathrm{P}<0.001)$ and the interaction between time and treatment regimen $(\mathrm{F}=7.987 ; \mathrm{P}<0.001)$ were found to be significantly different. For the interaction between time and treatment regimen, one-way ANOVA measuring the independent effects of treatment regimen at a specific time point was performed. There was no significant difference among the treatment regimens on days 11-13. However, on day 14, TAA treatment $(150 \mathrm{mg} / \mathrm{kg}$, intraperitoneally) significantly reduced the body weight of the animals compared with that of control animals (Fig. 4A), whilst NaHS treatment (100 $\mu \mathrm{mol} / \mathrm{kg} / \mathrm{day}$, intraperitoneally) prevented weight loss in TAA-treated mice compared with mice in the TAA-treatment alone group $(\mathrm{P}=0.017$; Fig. 4B). In addition, no significant differences were noted in the body weight between the mice in the control and those in the $\mathrm{H}_{2} \mathrm{~S}$-alone-treated groups (Fig. 4C). These results suggest that $\mathrm{H}_{2} \mathrm{~S}$ pre-treatment prevented weight loss in ALF mice.

$\mathrm{H}_{2} \mathrm{~S}$ attenuates cognitive deficiency as determined by the NOR test. In the present study, the effect of $\mathrm{H}_{2} \mathrm{~S}$ treatment on TAA-induced cognitive dysfunction was subsequently investigated. The mice were pre-treated with NaHS for 11 days and co-treated with TAA for an additional 3 days, following which cognitive function was investigated using the NOR test. No significant differences were noted in the time of total object exploration among the five groups of mice (Fig. 5A). The discrimination index in the TAA-treated mice were found to be significantly decreased compared with that noted in the control group (Fig. 5B). However, NaHS treatment (30 or $100 \mu \mathrm{mol} / \mathrm{kg} /$ day, intraperitoneal administration) 
A

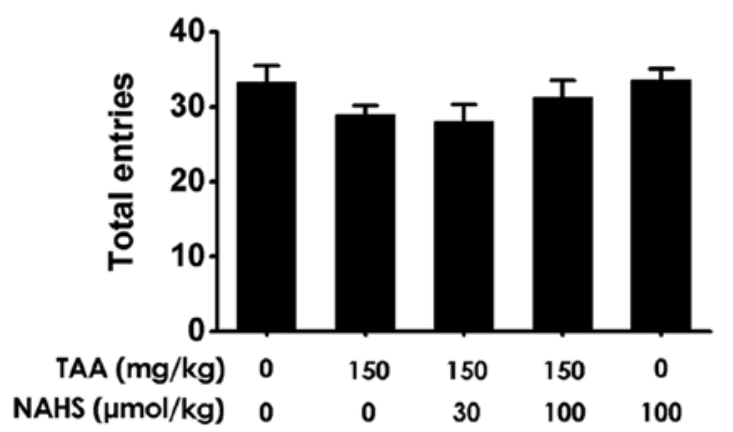

B

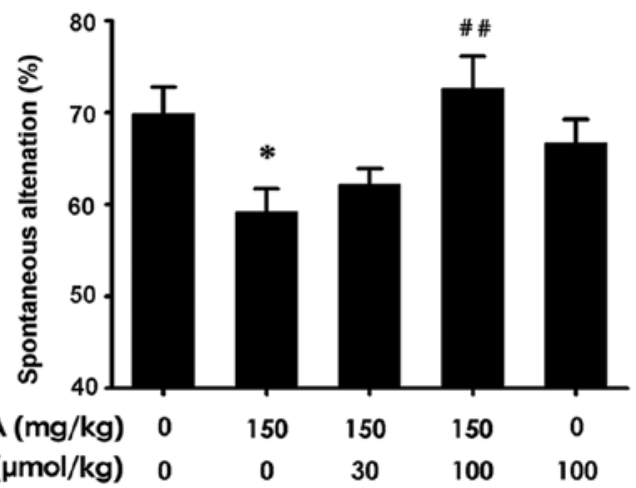

Figure 6. Effect of $\mathrm{H}_{2} \mathrm{~S}$ on the spatial orientation learning ability of mice. After treatment with saline or NaHS (30 and $100 \mu$ mol/kg/day, intraperitoneally) for 11 days followed by co-treatment with TAA $(150 \mathrm{mg} / \mathrm{kg}$, intraperitoneally) for 3 days, respectively, the mice were subjected to the Y-maze test. (A) The total number of arm entries and (B) spontaneous alternations were recorded. Values are presented as the mean $\pm \mathrm{SEM}$. $\mathrm{n}=9-15$. ${ }^{*} \mathrm{P}<0.05$ vs. control; ${ }^{\# \#} \mathrm{P}<0.01$ vs. TAA. H2S, hydrogen sulfide; TAA, thioacetamide; NaHS, sodium hydrogen sulfide.
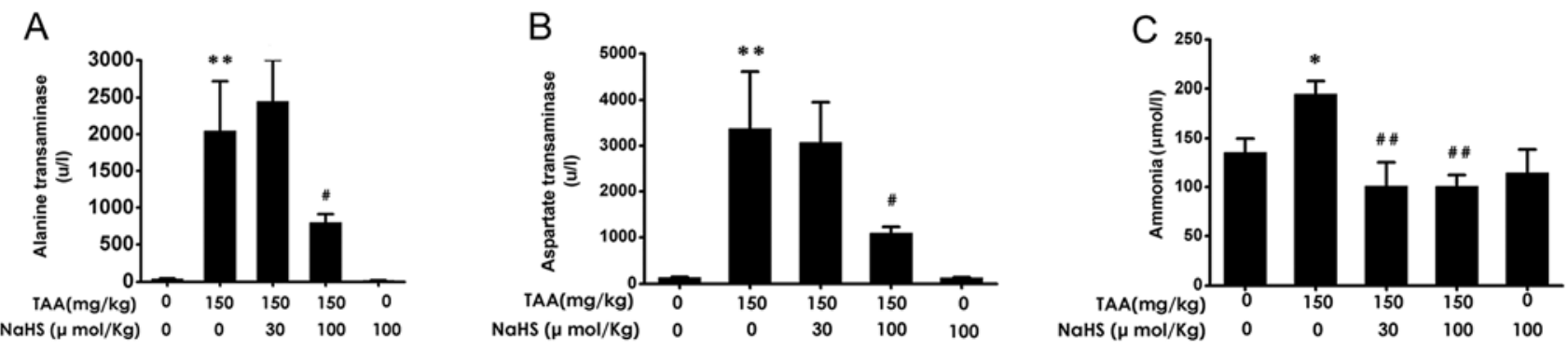

Figure 7. Effect of $\mathrm{H}_{2} \mathrm{~S}$ on the serum levels of liver enzymes and ammonia in mice. The serum levels of (A) ALT, (B) AST, and (C) ammonia were measured on the last day of the experiment. Values are presented as the mean \pm SEM. $n=6-9 .{ }^{*} \mathrm{P}<0.05$ vs. control; ${ }^{* *} \mathrm{P}<0.01$ vs. control; ${ }^{\#} \mathrm{P}<0.05$ vs. TAA; ${ }^{\# \#} \mathrm{P}<0.01 \mathrm{vs}$. TAA. ALT, alanine transaminase; AST, aspartate transaminase; TAA, thioacetamide; NaHS, sodium hydrogen sulfide.

significantly increased the discrimination index compared with that in the TAA treatment alone group (Fig. 5B). These results suggested that $\mathrm{H}_{2} \mathrm{~S}$ ameliorated cognitive deficiency triggered by the TAA injection.

$\mathrm{H}_{2} \mathrm{~S}$ improves spatial orientation learning ability in the $Y$-maze test. To investigate further whether $\mathrm{H}_{2} \mathrm{~S}$ treatment improved the spatial orientation learning ability of mice with ALF, the animals were subjected to the Y-maze test. No significant differences were observed in the number of total entries among the 5 groups of mice (Fig. 6A). Spontaneous alternations in the TAA-treated mice were revealed to be significantly decreased compared with those noted in the control group (Fig. 6B). However, NaHS administration (100 $\mu \mathrm{mol} / \mathrm{kg} / \mathrm{day}$, intraperitoneally) increased the spontaneous alternations in the TAA-treated mice compared with those treated with TAA alone. The results suggested that $\mathrm{H}_{2} \mathrm{~S}$ treatment protected mice from spatial orientation learning ability impairment triggered by TAA administration.

$\mathrm{H}_{2} \mathrm{~S}$ decreased serum levels of ALT, AST and ammonia after TAA treatment. AST, ALT and ammonia serum levels were next measured among the five groups. TAA administration (150 mg/kg, intraperitoneally) resulted in significant increases in serum ALT, AST and ammonia levels in comparison with control treatment (Fig. 7A-C). TAA co-administration in the presence of NaHS $(100 \mu \mathrm{mol} / \mathrm{kg} / \mathrm{day}$, intraperitoneally) caused significant reductions in the serum levels of ALT, AST and ammonia compared with TAA alone (Fig. 7A-C). These results suggested that $\mathrm{H}_{2} \mathrm{~S}$ treatment reduced liver dysfunction induced by TAA administration.

\section{Discussion}

TAA administration induces ALF, leading to cognitive deficiency and hepatic dysfunction in mice $(17,24)$. Previous studies have provided evidence that endogenous $\mathrm{H}_{2} \mathrm{~S}$ exerts a series of protective effects on the brain and liver (25-27). The aim of the present study was to investigate the role of $\mathrm{H}_{2} \mathrm{~S}$ treatment in TAA-induced mouse models of ALF where the potential therapeutic value of $\mathrm{H}_{2} \mathrm{~S}$ in this mouse model was also evaluated. The main findings were as follows: i) $\mathrm{H}_{2} \mathrm{~S}$ treatment appeared to alleviate cognitive deficiency and preserve spatial orientation learning ability in mice treated with TAA according to NOR and Y-maze test data, respectively; and ii) $\mathrm{H}_{2} \mathrm{~S}$ treatment appeared to reduce serum levels of ALT, AST and ammonia, in addition to preventing weight loss in TAA-treated mice. Therefore, $\mathrm{H}_{2} \mathrm{~S}$ treatment is suggested to exhibit protective effects on both brain and liver function in ALF mice.

TAA-induced ALF is a well-established rodent ALF model (28). The Y-maze and NOR tests are widely used as robust assays for assessing the cognitive function in mice (28). In the NOR test, NaHS administration led to marked increases 
in the discrimination index in the TAA-treated mice compared with mice treated with TAA alone, suggesting a protective effect of $\mathrm{H}_{2} \mathrm{~S}$ on cognition. The protective action of $\mathrm{H}_{2} \mathrm{~S}$ on cognition was confirmed further according to data obtained using the $\mathrm{Y}$ maze test. Compared with the control treatment, TAA treatment resulted in a reduction in spontaneous alternation, an effect that was reversed by $\mathrm{H}_{2} \mathrm{~S}$ treatment. These findings suggest that $\mathrm{H}_{2} \mathrm{~S}$ alleviated cognitive deficiency induced by TAA. A previous study conducted by our group (23) indicated that $\mathrm{H}_{2} \mathrm{~S}$ application ameliorated cognitive dysfunction in a chronic restrain stress (CRS)-induced rat model, where $\mathrm{H}_{2} \mathrm{~S}$ reversed the production of malondialdehyde and the reductions in superoxide dismutase activity and glutathione levels, demonstrating that it could protect against CRS-induced oxidative stress in the brain. To uncover the underlying molecular mechanisms of this protective action of $\mathrm{H}_{2} \mathrm{~S}$ further, additional biochemical experiments are required in future studies.

The serum levels of ALT and AST are sensitive markers for measuring liver injury $(10,29)$. To investigate the effect of $\mathrm{H}_{2} \mathrm{~S}$ on liver function, the serum levels of ALT, AST and ammonia were measured. $\mathrm{H}_{2} \mathrm{~S}$ significantly reduced the serum levels of ALT and AST, suggesting that $\mathrm{H}_{2} \mathrm{~S}$ exerted a hepato-protective effect. However, in a previous study, NaHS administration $(0.15 \mathrm{mmol} / \mathrm{kg}$, intraperitoneally) in rats augmented ALT and AST serum levels in the TAA-treatment group, suggesting that $\mathrm{H}_{2} \mathrm{~S}$ treatment aggravated liver injury and manifested hepatotoxic effects (30). Different NaHS concentrations may be the cause of the aforementioned discrepancies. A previous study reported that NaHS administration in mice resulted in increased liver myeloperoxidase (MPO) activity, which is a marker of tissue neutrophil infiltration and tumor necrosis factor- $\alpha$ levels in the plasma (31). These results indicated a pro-inflammatory effect of $\mathrm{H}_{2} \mathrm{~S}$. By contrast, administration of the CSE inhibitor DL-propargylglycine $(50 \mathrm{mg} / \mathrm{kg}$; intraperitoneally) exhibited marked anti-inflammatory activity by reducing liver MPO activity and tissue damage (31). In addition, $\mathrm{H}_{2} \mathrm{~S}$ has been reported to induce a biphasic concentration-dependent effect (32). In the present study, it was observed that NaHS treatment (30 or $100 \mu \mathrm{mol} / \mathrm{kg} / \mathrm{day}$, intraperitoneal administration) manifested neuroprotective effects on TAA-treated mice, consistent with the previous study (33). Therefore, low and increased levels of $\mathrm{H}_{2} \mathrm{~S}$ exhibited cytoprotective and cytotoxic effects, respectively (34). HE is a common complication in patients with ALF, which is associated with poor prognosis (35). Hyperammonemia is strongly implicated in the pathogenesis of hepatic encephalopathy that can cause brain edema, oxidative stress and inflammation (36). Hyperammonemia can also affect hepatocyte function (37). The present study indicated that $\mathrm{H}_{2} \mathrm{~S}$ treatment reversed the increased serum ammonia levels in TAA-treated mice, suggesting that $\mathrm{H}_{2} \mathrm{~S}$ treatment inhibited the development of hepatic encephalopathy by preserving liver function. Histological analysis in an ALF model will be performed in future research, to verify the aforementioned conclusions.

The present study did not directly measure $\mathrm{H}_{2} \mathrm{~S}$ levels, which is considered a limitation and should be assessed in a future study. Additionally, $\mathrm{H}_{2} \mathrm{~S}$ pretreatment for 11 days can be considered excessive, where $\mathrm{H}_{2} \mathrm{~S}$ concentration in the body may have been compensated for before TAA injection. Follow-up studies should therefore assess $\mathrm{H}_{2} \mathrm{~S}$ concentrations in the blood and liver tissues or cerebrospinal fluid, in addition to adjusting the $\mathrm{H}_{2} \mathrm{~S}$ pretreatment time. In the present study, NaHS was applied as the donor of $\mathrm{H}_{2} \mathrm{~S}$. Interestingly, Shirozu et al (6) reported that sodium thiosulfate, another donor of $\mathrm{H}_{2} \mathrm{~S}$, also attenuated liver injury in mouse models of acute liver failure. Therefore, sodium thiosulfate could have been adopted as an alternative donor of $\mathrm{H}_{2} \mathrm{~S}$ in a further study.

In conclusion, the present study demonstrated that $\mathrm{H}_{2} \mathrm{~S}$ treatment alleviated cognitive deficiency and hepatic impairment in an ALF mouse model. The current findings indicate that $\mathrm{H}_{2} \mathrm{~S}$ treatment exerts combined beneficial effects on the brain and liver in ALF mice, which may serve as a protective molecule against ALF. However, the precise mechanisms underlying the protective effect of $\mathrm{H}_{2} \mathrm{~S}$ in ALF remain elusive. Future studies should examine the molecular mechanisms underlying the aforementioned physiological processes. In addition, clinical studies are required to determine the potential clinical application of $\mathrm{H}_{2} \mathrm{~S}$ in the therapy of ALF.

\section{Acknowledgements}

Not applicable.

\section{Funding}

The presrnt study was supported by a Project of Research-based Learning and Innovative Experiments for Undergraduate Students grant (grant no. 2018XJXZ145).

\section{Availability of data and materials}

The datasets used and/or analyzed during the current study are available from the corresponding authors on reasonable request.

\section{Authors' contributions}

DSY, YQH, YJF, JX, YLH, SSZ, and PYS performed the experiments and analyzed the data. XQT was accountable for all the aspects of the work and responsible for final approval of the version to be published. DSY, YQH, YJF and XQT were responsible for manuscript writing and revision and experimental design. All authors approved the final version of the manuscript and figures.

\section{Ethics approval and consent to participate}

All experiments were conducted in accordance with the National Institutes of Health Guide for the Care and Use of Laboratory Animals and were approved by the Animal Use and Protection Committee of the University of South China (approval no. 1807022; Hengyang, China).

\section{Patient consent for publication}

Not applicable.

\section{Competing interests}

The authors declare that they have no competing interests. 


\section{References}

1. Stravitz RT, Kramer AH, Davern T, Shaikh AO, Caldwell SH, Mehta RL, Blei AT, Fontana RJ, McGuire BM, Rossaro L, et al; Acute Liver Failure Study Group: Intensive care of patients with acute liver failure: Recommendations of the U.S. Acute Liver Failure Study Group. Crit Care Med 35: 2498-2508, 2007.

2. Trey $\mathrm{C}$ and Davidson CS: The management of fulminant hepatic failure. Prog Liver Dis 3: 282-298, 1970.

3. Felipo V: Hepatic encephalopathy: Effects of liver failure on brain function. Nat Rev Neurosci 14: 851-858, 2013.

4. Poordad FF: Presentation and complications associated with cirrhosis of the liver. Curr Med Res Opin 31: 925-937, 2015.

5. Lee WM: Acute liver failure. N Engl J Med 329: 1862-1872, 1993.

6. Shirozu K, Tokuda K, Marutani E, Lefer D, Wang R and Ichinose F: Cystathionine $\gamma$-lyase deficiency protects mice from galactosamine/lipopolysaccharide-induced acute liver failure. Antioxid Redox Signal 20: 204-216, 2014.

7. Chen WL, Xie B, Zhang C, Xu KL, Niu YY, Tang XQ, Zhang P, Zou W, Hu B and Tian Y: Antidepressant-like and anxiolytic-like effects of hydrogen sulfide in behavioral models of depression and anxiety. Behav Pharmacol 24: 590-597, 2013.

8. Mani S, Cao W, Wu L and Wang R: Hydrogen sulfide and the liver. Nitric Oxide 41: 62-71, 2014.

9. Fiorucci S, Antonelli E, Mencarelli A, Orlandi S, Renga B, Rizzo G, Distrutti E, Shah V and Morelli A: The third gas: $\mathrm{H}_{2} \mathrm{~S}$ regulates perfusion pressure in both the isolated and perfused normal rat liver and in cirrhosis. Hepatology 42: 539-548, 2005.

10. Tan G, Pan S, Li J, Dong X, Kang K, Zhao M, Jiang X, Kanwar JR, Qiao H, Jiang $H$ and Sun X: Hydrogen sulfide attenuates carbon tetrachloride-induced hepatotoxicity, liver cirrhosis and portal hypertension in rats. PLoS One 6: e25943, 2011.

11. Kang K, Zhao M, Jiang H, Tan G, Pan S and Sun X: Role of hydrogen sulfide in hepatic ischemia-reperfusion-induced injury in rats. Liver Transpl 15: 1306-1314, 2009.

12. Tan BH, Wong PT and Bian JS: Hydrogen sulfide: A novel signaling molecule in the central nervous system. Neurochem Int 56: 3-10, 2010.

13. Giuliani D, Ottani A, Zaffe D, Galantucci M, Strinati F, Lodi R and Guarini S: Hydrogen sulfide slows down progression of experimental Alzheimer's disease by targeting multiple pathophysiological mechanisms. Neurobiol Learn Mem 104: 82-91, 2013.

14. Xuan A, Long D, Li J, Ji W, Zhang M, Hong L and Liu J: Hydrogen sulfide attenuates spatial memory impairment and hippocampal neuroinflammation in beta-amyloid rat model of Alzheimer's disease. J Neuroinflammation 9: 202, 2012.

15. National Research Council (US) Committee for the Update of the Guide for the Care and Use of Laboratory Animals: Guide for the Care and Use of Laboratory Animals, 8th edition. National Academies Press (US), Washington, DC, 2011.

16. Zimmermann C, Ferenci P, Pifl C, Yurdaydin C, Ebner J, Lassmann H, Roth E and Hörtnagl H: Hepatic encephalopathy in thioacetamide-induced acute liver failure in rats: Characterization of an improved model and study of amino acid-ergic neurotransmission. Hepatology 9: 594-601, 1989.

17. Avraham Y, Grigoriadis N, Poutahidis T, Vorobiev L, Magen I, Ilan Y, Mechoulam R and Berry E: Cannabidiol improves brain and liver function in a fulminant hepatic failure-induced model of hepatic encephalopathy in mice. Br J Pharmacol 162 : $1650-1658,2011$

18. Avraham Y, Grigoriadis NC, Magen I, Poutahidis T, Vorobiav L, Zolotarev O, Ilan Y, Mechoulam R and Berry E: Capsaicin affects brain function in a model of hepatic encephalopathy associated with fulminant hepatic failure in mice. $\mathrm{Br} \mathrm{J}$ Pharmacol 158: 896-906, 2009.

19. Panikashvili D, Simeonidou C, Ben-Shabat S, Hanus L, Breuer A, Mechoulam R and Shohami E: An endogenous cannabinoid (2-AG) is neuroprotective after brain injury. Nature 413: 527-531, 2001.
20. Avraham Y, Israeli E, Gabbay E, Okun A, Zolotarev O, Silberman I, Ganzburg V, Dagon Y, Magen I, Vorobia L, et al: Endocannabinoids affect neurological and cognitive function in thioacetamide-induced hepatic encephalopathy in mice. Neurobiol Dis 21: 237-245, 2006.

21. Li M, Zhang P, Wei HJ, Li MH, Zou W, Li X, Gu HF and Tang XQ: Hydrogen sulfide ameliorates homocysteine-induced cognitive dysfunction by inhibition of reactive aldehydes involving upregulation of ALDH2. Int J Neuropsychopharmacol 20: 305-315, 2017.

22. Ye T, Meng X, Wang R, Zhang $C$, He S, Sun G and Sun $X$ : Gastrodin alleviates cognitive dysfunction and depressive-like behaviors by inhibiting ER stress and NLRP3 inflammasome activation in db/db mice. Int J Mol Sci 19: E3977, 2018.

23. Li XN, Chen L, Luo B, Li X, Wang CY, Zou W, Zhang P, You Y, Tang XQ: Hydrogen sulfide attenuates chronic restrain stress-induced cognitive impairment by upreglulation of Sirt1 in hippocampus. Oncotarget 8: 100396-100410, 2017.

24. Avraham Y, Zolotarev O, Grigoriadis NC, Poutahidis T, Magen I, Vorobiav L, Zimmer A, Ilan Y, Mechoulam R and Berry EM: Cannabinoids and capsaicin improve liver function following thioacetamide-induced acute injury in mice. Am J Gastroenterol 103: 3047-3056, 2008.

25. Wu DD, Wang DY, Li HM, Guo JC, Duan SF and Ji XY: Hydrogen Sulfide as a Novel Regulatory Factor in Liver Health and Disease. Oxid Med Cell Longev 2019: 3831713, 2019.

26. Chen WL, Niu YY, Jiang WZ, Tang HL, Zhang C, Xia QM and Tang XQ: Neuroprotective effects of hydrogen sulfide and the underlying signaling pathways. Rev Neurosci 26: 129-142, 2015.

27. Panthi S, Chung HJ, Jung J and Jeong NY: Physiological Importance of Hydrogen Sulfide: Emerging Potent Neuroprotector and Neuromodulator. Oxid Med Cell Longev 2016: 9049782 , 2016

28. Chen SM, Yi YL, Zeng D, Tang YY, Kang X, Zhang P, Zou W and Tang XQ: Hydrogen Sulfide Attenuates $\beta 2$-MicroglobulinInduced Cognitive Dysfunction: Involving Recovery of Hippocampal Autophagic Flux. Front Behav Neurosci 13: 244, 2019.

29. Bae J, Min YS, Nam Y, Lee HS and Sohn UD: Humulus japonicus Extracts Protect Against Lipopolysaccharide/ d-Galactosamine-Induced Acute Liver Injury in Rats. J Med Food 21: 1009-1015, 2018.

30. Wang X, Wang B, Huang Q, Zhang B and Hua Z: Regulation of hydrogen sulfide on transporter protein Bsep and Mdr2 in acute liver failure. Zhonghua Yi Xue Za Zhi 95: 3176-3179, 2015 (In Chinese)

31. Li L, Bhatia M, Zhu YZ, Zhu YC, Ramnath RD, Wang ZJ, Anuar FB, Whiteman M, Salto-Tellez M and Moore PK: Hydrogen sulfide is a novel mediator of lipopolysaccharide-induced inflammation in the mouse. FASEB J 19: 1196-1198, 2005.

32. Wedmann R, Bertlein S, Macinkovic I, Boltz S, Miljkovic J, Munoz LE, Herrmann M and Filipovic MR: Working with ' $\mathrm{H}_{2} \mathrm{~S}$ ': facts and apparent artifacts. Nitric Oxide 41: 85-96, 2014.

33. Yakovlev AV, Kurmasheva ED, Giniatullin R, Khalilov I and Sitdikova GF: Hydrogen sulfide inhibits giant depolarizing potentials and abolishes epileptiform activity of neonatal rat hippocampal slices. Neuroscience 340: 153-165, 2017.

34. Brown KG and Strickland JA: Utilizing data from multiple studies (meta-analysis) to determine effective dose-duration levels. Example: Rats and mice exposed to hydrogen sulfide. Regul Toxicol Pharmacol 37: 305-317, 2003.

35. Schwendimann RN and Minagar A: Liver Disease and Neurology. Continuum (Minneap Minn) 23 (3, Neurology of Systemic Disease): 762-777, 2017.

36. Shawcross D and Jalan R: The pathophysiologic basis of hepatic encephalopathy: Central role for ammonia and inflammation. Cell Mol Life Sci 62: 2295-2304, 2005.

37. Wang Q, Wang Y, Yu Z, Li D, Jia B, Li J, Guan K, Zhou Y, Chen Y and Kan Q: Ammonia-induced energy disorders interfere with bilirubin metabolism in hepatocytes. Arch Biochem Biophys 555-556: 16-22, 2014. 